\title{
Integrating public risk perception into formal natural hazard risk assessment
}

\author{
Th. Plattner ${ }^{1}$, T. Plapp ${ }^{2}$, and B. Hebel ${ }^{1}$ \\ ${ }^{1}$ Land Use Engineering, Swiss Federal Institute of Technology, Zurich, Switzerland \\ ${ }^{2}$ Institute for Insurance, University of Karlsruhe (TH), Karlsruhe, Germany \\ Received: 1 September 2005 - Revised: 3 April 2006 - Accepted: 12 April 2006 - Published: 7 June 2006
}

\begin{abstract}
An urgent need to take perception into account for risk assessment has been pointed out by relevant literature, its impact in terms of risk-related behaviour by individuals is obvious. This study represents an effort to overcome the broadly discussed question of whether risk perception is quantifiable or not by proposing a still simple but applicable methodology. A novel approach is elaborated to obtain a more accurate and comprehensive quantification of risk in comparison to present formal risk evaluation practice. A consideration of relevant factors enables a explicit quantification of individual risk perception and evaluation.

The model approach integrates the effective individual risk $r_{\text {eff }}$ and a weighted mean of relevant perception affecting factors PAF. The relevant PAF cover voluntariness of risktaking, individual reducibility of risk, knowledge and experience, endangerment, subjective damage rating and subjective recurrence frequency perception. The approach assigns an individual weight to each PAF to represent its impact magnitude. The quantification of these weights is target-groupdependent (e.g. experts, laypersons) and may be effected by psychometric methods.

The novel approach is subject to a plausibility check using data from an expert-workshop. A first model application is conducted by means of data of an empirical risk perception study in Western Germany to deduce PAF and weight quantification as well as to confirm and evaluate model applicbility and flexibility.

Main fields of application will be a quantification of risk perception by individual persons in a formal and technical way e.g. for the purpose of risk communication issues in illustrating differing perspectives of experts and non-experts. For decision making processes this model will have to be applied with caution, since it is by definition not designed to quantify risk acceptance or risk evaluation. The approach
\end{abstract}

Correspondence to: Th. Plattner

(thomas.plattner@env.ethz.ch) may well explain how risk perception differs, but not why it differs. The formal model generates only "snap shots" and considers neither the socio-cultural nor the historical context of risk perception, since it is a highly individualistic and noncontextual approach.

\section{Introduction}

During the past years a significant change in Swiss hazard management policy took place, which is due to an underlying general paradigm shift. One implication is a rising importance of the concept of risk. Before the policy change, for many years responsible authorities had aimed at achieving standardised safety levels through prevention of hazardous processes, regardless what the cost of the required measures was. Nowadays, however, a need for optimised resource usage arises due to limited financial resources and growing public interest in its allocation. The risk concept enables the authorities to economically optimise their investments. As a consequence, the objective of natural hazard risk management is no longer an absolute (and sometimes economically unreasonable) safety level, but the identification of costeffective risk mitigation measures. Optimisation shall reduce the maximum magnitude of an effective risk at a lowest possible price to an individually and socially acceptable level.

As a part of the risk management process, risk evaluation defines that level of acceptable risk. Thus, it answers the question "what may happen?". In the literature, two main concepts of risk evaluation using different approaches and methodologies are predominant:

Published by Copernicus GmbH on behalf of the European Geosciences Union. 
- so-called "intuitive" processes of risk perception and evaluation performed by individuals and groups for their everyday decisions about the acceptability of risks;

- formal, technical processes of risk evaluation, which are mainly used by official authorities identifying a normatively defined acceptable risk $r_{\text {norm }}$.

The factors determining these public risk perception and evaluation processes have been investigated in numerous empirical studies by economists, psychologists and social scientists.

On the other hand, various technical approaches for formal risk evaluation were elaborated. One of their objectives is to consider the findings of public risk perception and evaluation studies and to integrate the known relevant factors of risk perception. However, they are so far limited to taking the extent of damage into account. Consequently, these approaches exclude further aspects relevant for individual risk perception, such as socio-psychological risk dimensions. This incomplete integration of risk perception and evaluation is the main shortcoming of the current practice.

In order to obtain a more accurate and comprehensive quantification of risk new approaches are therefore needed. Approaches that consider the full spectrum of factors relevant for risk perception and evaluation are particularly promising in this context, since they enable a quantification of individual risk perception and risk evaluation .

The present paper proposes a formal approach to integrate individual risk perception within an objective risk function. The model is mainly based on an expressed preferences approach (e.g. (Fischhoff et al., 1978), which represents one of the most seminal findings of risk perception research during the last three decades. The objective of this paper is to propose a formalised approach that considers quantified effective individual risk while integrating subjective risk perception. The elaboration of such a novel model concept is motivated by the fact that findings of expressed preferences approaches are relevant for risk management and risk communication. First application results of the proposed approach are displayed, using data from a empirical risk perception study conducted by Plapp (2004) in Western and Southern parts of Germany.

\section{State of knowledge}

Within the risk management process, risk evaluation answers the question "what may happen?" and thus helps to define the acceptable level of risk. So far, two main risk approaches are known.

- within the natural hazard risk management community, risk is usually defined in a formal way as product of the effective probability of a given size and the predicted level of damage it would cause (see Eq. 1);
- decades of psychological and social scientific research have shown that the everyday processes of risk perception and risk evaluation rely on entirely different models to subjectively assess risks.

Compared to the first mentioned formal risk definition, the cognitive and affective structure of risk is more complex and encompasses more dimensions than merely figures for occurrence probability and possible damage of an event. Empirical studies of risk perception showed that - besides quantitative factors or dimensions such as perceived damage and perceived recurrence frequency - also qualitative dimensions represent relevant factors for individual risk perception (Slovic, 1987; Fischhoff et al., 1978).

\subsection{The "objective" and rational concept of risk}

In risk management literature, the individual effective risk $r_{\text {eff }}$ is usually defined as

$r_{\mathrm{eff}, \mathrm{i}}=p_{\mathrm{obj}, \mathrm{i}} \cdot e_{\mathrm{eff}, \mathrm{i}}$

i.e., as product of the effective damage of an event $e_{\mathrm{eff}, \mathrm{i}}$ times the effective occurrence probability $p_{\text {eff,i }}$ of the event $i$. Thus, reducing the extent of effective damage $e_{\text {eff }}$ or the effective occurrence probability $p_{\text {eff }}$ will lower the effective risk $r_{\text {eff. }}$.

This formal "objective" risk definition is based on the rational expected value model of human behaviour. According to Simon $(1955,1966)$, that model is based on the assumption that people

- have full information about all relevant aspects of an observed system, or at least, comprehensive and clear information about that very system,

- have a well organised and stable system of preferences,

- are able to define a value for several known alternatives on their scale of preferences, and to prioritise these according to their utility; this requires knowlege about the possible alternatives for action, and to possess a function to allocate an unambiguous utility to each of these alternatives.

To achieve an optimal risk management, however, also the societal level of acceptable risk has to be determined. Decision-making authorities have to define the level of safety that has to be achieved. Formal risk evaluation approaches are frequently used to identify the required safety goals, and thus to answer the question of "what may happen?". Currently, and in most cases acceptable risk $r_{\text {norm }}$ is thereby defined by experts, based on standards, empirical considerations, and intuition as well. The acceptability of a certain risk can be defined using normative criteria to either allow a risk, to denote it as inadmissible, or to ascertain a risk level for which acceptability can prospectively be expected 
(NDK, 2001). After Heinimann (2002) the acceptable risk $r_{\text {norm }}$ should be defined within a political process of opinion forming, involving experts, stakeholders, pressure groups, as well as political decision-makers.

\subsection{The subjective concept of risk}

Several empirical studies highlighted the systematic discrepancy between the individual, subjective risk evaluation and the formal risk evaluation procedures. Hence, considering and integrating subjective aspects becomes a basic requirement. Three decades of research on individual and social risk perception as well as risk evaluation revealed that the everyday and subjective risk perception by "laypersons" is anything else than "irrational", but follows underlying plausible rules. They are yet quite different from the rational rules for formal risk evaluation conducted by "experts", which leads to systematic deviation between individual and formal risk evaluation (Slovic et al., 1981, 1982, 1986; Slovic, 1987, 2000). According to Fischhoff et al. (1978), a number of qualitative and quantitative risk dimensions influence the individual perception and evaluation of a risk: The voluntariness of risk-taking, the knowledge about a certain risk, the dread associated with the risk, the immediacy, irreversibility and intensity of impacts, the possibilities to control or reduce the risk, and others. Thus, the risk concept is described as a multidimensional construct within psychological and social science risk research (Slovic, 1992; Kasperson et al., 1988).

According to several studies (Fischhoff et al., 1981; Griesmeyer, 1982; Geiger, 1993; Marris et al., 1997; Jasanoff, 1998; Belzer, 2001; Skjong and Wentworth, 2001; Siegrist et al., 2004), the existence of a strong inter-individual variation within risk perception, and, furthermore, a systematic difference between experts' and laypersons' risk perception can be assumed. This difference is said to be related to the various kind of dimensions used in risk evaluation, and to the priorities that are associated with these dimensions, respectively. While experts refer to more "quantitative" and formal criteria such as the probability and the expected effective damage of a certain event, laypersons are said to additionally rely on the mentioned qualitative criteria or dimensions (Slovic, 1987). Although this principal difference in the underlying concepts of experts and laypersons has been doubted (Rowe and Wright, 2001), risk judgements of different persons have nevertheless to be considered as strongly deviating because of varying social contexts, including different social roles and role expectations.

Psychometric approaches using field studies and questionnaires are very common methods for risk perception studies of technical hazards (Slovic, 1992; Rohrmann, 1999). Recent research even proved their applicability to natural hazards (Finlay and Fell, 1997; Lima, 1997; DeChano and Butler, 2001; Plapp, 2004; Siegrist et al., 2004). Experimental research on human behaviour, i.e. on preferences and decision making theories (Kahneman and Tversky, 1979; Tversky and
Kahneman, 1992; Eisenführ and Weber, 2003; Neumann and Morgenstern, 2004), moreover showed that individuals

- tend to overestimate small probabilities and to underestimate medium and large probabilities, and

- tend to derive perceived damage in a non-linear way from the extent of effective damage (defined as negative utility).

Further studies indicate that risk perception is in addition strongly influenced by media coverage of risk (Rohrmann, 1999). Besides that, risk perception is shaped by the sociocultural context and is dynamic, i.e. changes over time (Kasperson et al., 1988). Because of this complexity, risk perception prediction or even a deduction of general theory on risk perception appears to be difficult. Nevertheless, the importance of risk perception for an effective and socially accepted risk management is clearly evident (Renn, 1998; Pidgeon, 1998).

\subsection{Combining both concepts of risk}

Most formal risk evaluation approaches are based on the objective concept of risk. Nevertheless, some approaches try to integrate risk perception and risk evaluation by individuals and groups of individuals. Mostly, the well known influence of the effective extent of damage $e_{\text {eff }}$ on risk perception and evaluation is considered in approaches to evaluate acceptable, collective risk $R_{\text {norm }}$, e.g. within the approach of aversion function and acceptance line (Merz et al., 1995; Troxler et al., 1989; Bohnenblust, 1985; Bohnenblust and Schneider, 1984; Bohnenblust and Slovic, 1998; BUWAL, 1991; Farmer, 1967; Amman et al., 2004; BABS, 2003). In some cases even the aspect of voluntariness to take risks is regarded, particularly by introducing risk categories for acceptable individual risk $r_{\text {norm }}$ (Merz et al., 1995; Bohnenblust, 1985; Bohnenblust and Schneider, 1984; Bohnenblust and Slovic, 1998; Amman et al., 2004; BABS, 2003). Still, only a narrow selection of relevant risk perception factors is integrated in such approaches.

In an attempt to integrate both the formal and the socialpsychological perspective, Sandman (1989, 1999a,b) defines risk as a function of "hazard" and "outrage".

risk $=$ hazard + outrage

In this context hazard has to be regarded as the objective view of risk, focused on the effective damage extent and the occurrence probability of unwanted effects, and outrage is mainly focusing on the negative aspects of a situation. This theory can be comprehended as a rough approximation to the perceived risk. Sandman (1987) enumerates more than twenty "outrage"-factors, which shall at least partially explain the difference between perceived subjective and formally calculated effective risk. These factors were again drawn from psychometric studies. 
Slovic (1987) describes subjectively perceived risk as a systematical anomaly in the assessment of an individual risk, based on the formal quantitative measure of risk. Thus, a perceived risk may also be defined as the subjective view of the very risk, based on subjective processing and evaluation of risk-related information (NDK, 2001). Consequently, perceived risk may be expressed after

$r_{\text {perc }}=f\left(r_{\text {eff }}\right.$, bias $)$

as function of the effective risk $r_{\text {eff }}$ and a systematic deviation, which is specific for the regarded individual or social group (i.e. "bias"). Given this definition, even the acceptable risk $r_{\text {norm }}$ may be counted for a particular kind of the perceived risk, i.e. the systematical deviation of the experts' assessment from effective risk $r_{\text {eff }}$ (whereas the experts try to consider legal regulations and technical standards).

\section{Material and methods}

\subsection{Hypothesis}

Due to the findings of Sect. 2 this study is based on the hyopthesis whereupon different individuals and social groups which can be distinguished e.g. according to shared values, beliefs, educational background, etc. (e.g. laypersons vs. experts) attribute varying weights to the affecting factors of risk perception. Thus, quantified perceived risk is established as a function of perception affecting factors and corresponding weights.

3.2 Calculating the perceived risk: the equation, its basics and the parametrisation

The proposed approach to calculate the individual perceived risk is based on two different building blocks. First, it relies upon the objective and rational concept of risk, i.e. the effective individual risk $r_{\text {eff }}$ (cf. Eq. 1). Second, the individual subjective deviation of individual risk perception is considered, using relevant risk Perception Affecting Factors (PAF). Therefore, our proposal for an individual "risk perception" equation is

$r_{\text {perc }}=p_{\text {eff }} \cdot e_{\text {eff }} \cdot \frac{\sum_{i=1}^{n}\left(\text { paf }_{i} \cdot a_{i}\right)}{\sum_{i=1}^{n} a_{i}}$

with $\operatorname{paf}_{i}$ being the value of the perception affecting factor, $a_{i}$ being the weight for each $p a f_{i}$ and $n$ being the total quantity of relevant PAF. The parameters $p a f_{i}$ and $a_{i}$ were defined as subject to the following boundary conditions:

- the domain for $p a f_{i}$ is $[0.5,2]$

- the domain for $a_{i}$ is $[0,1]$

- paf $_{i}>1$ increase the perceived risk $r_{\text {perc }}$
- $\operatorname{paf}_{i}=1$ are indifferent or neutral concerning the perceived risk $r_{\text {perc }}$

- $p a f_{i}<1$ decrease the perceived risk $r_{\text {perc }}$

- the upper boundary paf $_{i}=2$ doubles the perceived risk $r_{\text {perc }}$

- the lower boundary pa $_{i}=0.5$ halves the perceived risk $r_{\text {perc }}$

3.3 Definition of PAF and experts-weights $a_{i, e x}$ within a workshop

The selection of the relevant PAF followed a detailed analysis of the psychometric risk perception literature and a compiled list of all mentioned risk dimensions. Prosecuting a qualitative Delphi-like approach, this list of risk dimensions was subsequently analysed according to the relevance for the domain of natural hazard by in total five experts. In doing so, all elements were also tested qualitatively one among another for collinearity. The resulting short list was compared with results of recent studies in the very domain, e.g. the work of Plapp (2004).

As final step, this short list was discussed with eighteen risk perception experts in a workshop held at the Swiss Federal Institute of Technology (ETH Zürich) in November 2004. One of the aims of the workshop was the significant definition of these PAF within the field of natural hazards using a Delphi-like procedure. Therefore, the remaining selection of PAF is called the workshop-PAF.

Known risk perception studies indicate that the relevant factors exert influence of different intensities. The model therefore assigns a specific weight $a_{i}$ to every PAF representing its impact magnitude. Within the mentioned workshop at the ETH, the quantification of the PAF-weighting is based on the Analytical Hierarchical Process (AHP) after Saaty (2001). The process delivered an expert-based ranking for the relevance of respective PAF, so that these weights are called experts-weights $a_{i, e x}$.

\subsection{Case study for plausibility check}

Knowing the relevant workshop-PAF and their specific experts-weighting $a_{i, e x}$, a plausibility and a sensitivity check was performed. For this purpose, the approach using the defined PAF together with the weights was applied to a constructed case study. The case study refers to a single river flooding event with an effective annual occurrence probability $p_{\text {eff }}=0.02$ (i.e. one flooding every fifty years), causing an effective individual damage $C_{\text {eff }}$ of 40000 .- Euro, resulting in an effective individual risk $r_{\text {eff }}$ of 800 .- Euro $\cdot a^{-1}$. 
3.5 Risk perception survey as a basis for experts- and laypersons-PAF and weights $a_{i}$

\subsubsection{Risk perception survey in Germany}

The formal model was further tested with empirical, real live data collected in a multi-hazard survey on natural hazard risk perception by one of the authors (Plapp, 2001, 2004; Plapp and Werner, 2006).

The psychometric paradigm of risk perception (Fischhoff et al., 1978; Slovic, 1987, 1992) had been applied on risk perception from storm, flood, and earthquake in a mail-out questionnaire in six affected regions in Southern and Western Germany in 2001: Cologne-Rodenkirchen, Passau, Neustadt a.d. Donau, Albstadt, Karlsruhe, and Rosenheim. The six survey areas had been selected using Munich Re's Disasters Catalogue for Germany (MünchenerRück, 1999) and other additional sources. Criteria for selection included the exposure to flood, windstorm, and earthquake, the type of settlement as well as the area's experience with natural hazards in the last 30 years. In total, 450 persons participated in the study, 223 of them female, 227 male. The average age was 48 years. The level of education in the sample is above average compared to the total population of Germany, which is a typical feature of mail-out questionnaires due to selfselection effects. Since after Sjöberg (2000a,b) the influence of education level on risk perception can be assumed to be fairly low, no bias due to the education level has to be expected. The vast majority of the participants have no special qualifications related to risk or hazard management to refer to them as "risk experts", thus they are considered as being "laypersons".

The psychometric approach in the survey employed nine risk dimensions that should explain the level of the perceived individual risk. Referring to studies on perception of natural and environmental risks (Brun, 1992; Karger and Wiedemann, 1998) the following risk dimensions had been selected:

- the perceived likelihood to die from the hazard

- the perceived degree of scientific knowledge about the risk

- the knowledge of the risk to those exposed (old or new risk)

- the emotion of fear evoked by the risk

- the possibilities to influence the risk

- the perceived recurrence frequency

- the predictability

- the expected future increase or decrease of the risk in terms of event frequency and intensity of impacts on society
- the willingness to move into a hazard area provided that there are better living conditions

The respondents had been asked to judge each of the three hazards regarding their individual perceived risk and regarding all nine risk dimensions, in each case on a 5-point scale.

\subsubsection{Transformation of the survey risk dimensions to the} workshop-PAF-meanings

In order to test the proposed model with the survey data, first the semantic meaning of the workshop-PAF and the empirical field study were compared. Correspondences and semantic overlapping of the risk dimensions used in the survey and the workshop-PAF were to be expected.

\subsubsection{Deduction of laypersons-weights $a_{i}$ for the workshop-PAF}

The survey responses can be used to determine the laypersons-weights of the workshop-PAF. The results can then be compared with those of the experts using the same formal model to test the impact of different weights on the same workshop-PAF.

The survey data had to be split into two data sets: one set for deducing the laypersons' ranking and weights of the workshop-PAF (model sample); and a second data set for applying the deduced values (test sample). The total sample of 450 respondents was split randomly in two samples of 273 , respectively 272 respondents, whereby a quota system was used to ensure that both samples contained equal proportions of respondents from each of the six survey areas. In both data sets, each respondent represents three cases, as responses for each of the three hazards (flood, storm and earthquake) were regarded as cases, a technique used also by Karger and Wiedemann (1998). Thus, the model sample consisted of 819 cases $(273 \times$ three hazards $)$ and the test sample of 816 cases (272 persons $\times$ three hazards). Both samples were then examined for comparability regarding the relevant variables.

The laypersons_1-weights $a_{i, \text { lay_1 }}$ for the workshop-PAF were derived from the data by multiple bivariate linear regression analysis. The individual perceived risk was the dependent variable, and the PAF-variables the independent variables. The regression weights $\beta$ represent the impact of a factor or variable on the dependent variable, i.e. the personal risk. To fit the regression weights to the range of $[0,1]$ as required by the boundary conditions (cf. Sect. 3.2) in order to obtain weights, the highest beta value was taken as 1 while the other were transformed respectively.

\subsubsection{Deduction of alternative PAF and weights $a_{i}$ for laypersons}

Using the model sample, the survey data allow to generate an alternative, empirical selection of major influencing factors of risk perception including their respective factor weights. 
Table 1. Transformation of empirical survey values Plapp (2004) into PAF-values with a value range $[0.5,2]$

\begin{tabular}{ll}
\hline $\begin{array}{l}\text { value in survey } \\
\text { Plapp (2004) }\end{array}$ & $\begin{array}{l}\text { PAF-value by } \\
\text { formal model }\end{array}$ \\
\hline 1 & 0.5 \\
1.5 & 0.625 \\
2 & 0.75 \\
2.5 & 0.875 \\
3 & 1 \\
3.5 & 1.25 \\
4 & 1.5 \\
4.5 & 1.75 \\
5 & 2 \\
\hline
\end{tabular}

The empirical selection of PAF can be applied to the formal "risk perception equation" Eq. 4 in its general form. In this way, also the impact of using different PAF can be studied.

The empirical survey data were used to deduce an additional empirically generated combination of PAF. For this purpose, again several regression analyses were performed, using also those risk dimensions as independent variables that had not been included in the workshop selection of PAF. These PAF are called questionnaire-PAF, based on their derivation from the survey data. Again, the regression weights $\beta$ were used to deduce weights by transforming them according to their magnitude. These weights are called

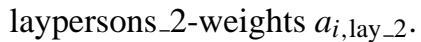

Finally, the values of the questionnaire-PAF had to be transformed into $\mathrm{paf}_{i}$-values ranging from 0.5 to 2 to fit to the boundary conditions of the PAF. In order to maintain the required domain according to the boundary conditions, the empirical values were transformed as indicated in Table 1. The empirical values of the risk dimensions in the survey were collected on a 5 point-scale ranging from 1 to 5 . The value range of the PAF-variable "endangerment" which was created by the mean of two variables comprised the additional values $[1.5, \ldots, 4.5]$.

\section{Results}

\subsection{Literature analysis and workshop: the results}

\subsubsection{Workshop-PAF and the experts-weights $a_{i, e x}$}

Based on the literature and the experts workshop mentioned in Sect. 3.3, a small number of relevant perception affecting factors PAF finally remained (cf. also Table 2, column 2):

- voluntariness of risk-taking: $p a f_{v}$,

- reducibility of risk: $p a f_{r}$,

- knowledge and experience: $p a f_{e x}$,
- endangerment: $p a f_{d}$,

- subjective damage rating: pafe,

- subjective recurrence frequency: $p a f_{f}$.

Their determined experts-weights $a_{i, e x}$ are shown in the second column of Table 3 .

\subsubsection{Plausibility check: the case study example}

Based on the workshop-PAF, the plausibility of the proposed approach for the calculation of the perceived individual risk (cf. Sect. 3.2) was checked using the case study mentioned in Sect. 3.4. Therefore, we assumed that one of the houseowners' individual perception affecting factors PAF can be deduced as follows (where paf $f_{i}$ is within [0.5,2] and verbally defined as "very low", "low", "moderate", "high", and "very high"):

- he bought his house voluntarily due to a very low price, knowing and accepting that it is situated within a flooding area. He therefore rates his voluntariness at "very high", resulting in a risk perception decreasing paf $_{v}=0.5$.

- the effective reduction of the effective risk for the specific area to be affected by flooding may only be realised by collective technical measures of flood prevention (such as a retention pond, flood embankment). The houseowner therefore rates his effective individual reducibility of the flood risk to be low (e.g. sandbags), resulting in a risk perception increasing pa $_{v}=1.50$.

- the person owns his house already for 30 years, during which his basement was already affected by flooding twice. He therefore rates his personal knowledge about the floods' occurrence, behaviour and effects to be high, resulting in a risk perception decreasing $p a f_{e x}=0.75$.

- according to the houseowner's view, the general individual endangerment of his and his family's subsistence and well-being by the regular floods is low, leading to a risk perception decreasing $p a f_{d}=0.75$.

- due to the two past flood events and the caused damage, the houseowner is able to appropriately specify the individual damage effect to his property (knowing about his individual damage value of 40000 .- Euro), resulting in an indifferent $\mathrm{paf}_{e}=1.00$.

- he on the other hand overestimates the recurrence frequency of floods within his living area due to the two witnessed events during past 30 years (in relation to the effective flood recurrence frequency of 50 years), which leads to a risk perception increasing $p a f_{p}=1.75$. 
Table 2. PAF definitions and corresponding variables from the questionnaire by Plapp (2004).

\begin{tabular}{lll}
\hline Workshop-PAF & Corresponding variables in questionnaire & PAF-Variable \\
\hline $\operatorname{paf}_{v}$ (voluntariness) & willingness to move into risk area & voluntariness \\
paf $_{r}$ (reducibility) & predictability, & influence \\
& possibilities to influence risk & \\
paf $_{d}$ (endangerment) & likelihood to die (li), fear evoked (fe) & mean of (li) and (fe) \\
paf $_{e x}$ (knowledge, experience) & familiarity, known to science & known to science \\
paf $_{e}$ (subjective damage rating) & not used as risk dimension & - \\
$\operatorname{paf}_{f}$ (subjective recurrence frequency) & frequency & frequency \\
\hline
\end{tabular}

Taking into account all $p a f_{i}$ and experts-weight $a_{i}$ as proposed by the authors, the perceived individual risk for the houseowner amounts to $r_{\text {perc }}=866.62$ Euro $\cdot a^{-1}$. This means, the owner overestimates his individual risk by $8 \%$.

4.2 Risk perception survey: the resulting PAF and their weights $a_{i}$

4.2.1 Workshop-PAF resulting from the survey risk dimensions transformation and their laypersons-weights $a_{i, \text { lay_1 }}$

Table 2 shows the list of identified relevant workshop-PAF (column 1) and corresponding variables from the survey (columns 2 and 3). For the PAF "endangerment" two corresponding survey variables were identified each showing a sufficient correlation with the perceived personal risk: the likelihood to die from the hazard $(r=0.46)$ and the fear evoked by the hazard $(r=0.60)$. The two risk dimensions themselves are also correlated with each other $(r=0.52)$. Instead of excluding one or the other, an index was created based on the mean of both variables. Unfortunately, there was no corresponding variable in the survey data for the workshop-PAF "subjective damage rating", as damage had been surveyed qualitatively in a way incompatible to the formal model. Despite of this correspondence missing, the overall level of correspondence was considered as sufficient and the workshop selection of PAF was applied to the empirical data. The laypersons_1-weights $a_{i, \text { lay_1 }}$ of these workshopPAF based on the risk perception survey are shown in column 4 in Table 3.

\subsubsection{Laypersons-PAF and their weights $a_{i, \text { lay_2 }}$ based on the risk perception survey}

Based on the method mentioned in Sect. 3.5.4 the relevant PAF and corresponding laypersons_2-weights $a_{i, \text { lay_2 }}$ listed in column 5 of Table 3 were derived from the survey data. Where the PAF generated during literature analysis and workshop are the same as those deduced from the survey data, also the resulting weights are the same. One additional relevant factor for individual risk perception emerged from the survey data: "future increase", i.e. the future expected in- crease of the risk in terms of event frequency and intensity of impacts on the society.

\subsection{Application to "real-life" data: testing the approach}

First the laypersons_1-weights $a_{i \text {, lay_1 }}$ were calculated based on the regression weights in the model sample $\beta$ and then transformed into weights $a_{i}$ ranging from 1 to 0 (cf. Table 3). Second, the regression weights $\beta$ for the resulting relevant risk dimensions of the empirically generated PAFselection were calculated and transformed into the laypersons_2-weights $a_{i}$, lay_2.

The application of the proposed risk perception equation (cf. Eq. 4) using the questionnaire-PAF differs slightly from the result using the workshop-PAF. One additional PAF, the "future expected increase" of natural hazards and their impacts, proved to be important. Within the questionnaireselection, the PAF "reducibility" was excluded from the list of relevant PAF as the regression weight $\beta$ failed the necessary level of significance. This PAF had been included in the workshop-selection for reasons of plausibility. Since the correlation coefficient between the perceived individual risk and the perceived possibilities to influence the risk (=reducibility) was statistical significant, even if very small $(r=0.07)$, and since the $\beta$ failed the level of significance very narrowly, it was decided to include it as relevant PAF in the workshop-selection of PAF. However, it was not included in the questionnaire-PAF list.

The application of the data was implemented in three different runs. For all three runs, the lay-data (test sample) were used as input values for the $p a f_{i}$ (transformed according to Table 1) while different weight schemes were used. In the first implementation, the laypersons- $\mathrm{paf}_{i}$-values were combined with the workshop-PAF and the experts-weights $a_{i, e x}$. In the second run, the workshop-PAF were combined with the laypersons_1-weights $a_{i, \text { lay_1 }}$ and in the third implementation the empirically generated questionnaire-PAF and the laypersons_2-weights $a_{i}$, lay_2 were used, finally.

Since the survey-data were not related to effective damage values or effective recurrence frequencies of that damage, both $p_{\text {eff }}$ and $e_{\text {eff }}$ were defined as 1 . Thus the effective individual risk $r_{\text {eff }}$ is 1 . For the damage-associated $p a f_{e}$ of 
Table 3. PAF and corresponding weights of the PAF, distinguished between workshop-selection of PAF with experts-weighting (result of the experts workshop, approach of Saaty (2001)) and laypersons-weighting deduced by data provided from Plapp (2004), and empirically deduced questionnaire-PAF and the respective weights.

\begin{tabular}{|c|c|c|c|c|}
\hline \multirow{4}{*}{$\begin{array}{l}\text { PAF definition } \\
\text { Group } \\
\text { Parameter }\end{array}$} & \multicolumn{3}{|c|}{ Workshop } & \multirow[t]{2}{*}{ Questionnaire } \\
\hline & Experts & & Laypersons & \\
\hline & $a_{i, e x}$ & $\beta_{i}$ & $a_{i, \text { lay_1 }}$ & $a_{i, \text { lay_2 }}$ \\
\hline & $\begin{array}{c}\text { Experts-weights } \\
{[0.0-1.0]}\end{array}$ & & $\begin{array}{c}\text { Laypersons_1-weights } \\
{[0.0-1.0]}\end{array}$ & $\begin{array}{c}\text { Laypersons_2-weights } \\
{[0.0-1.0]}\end{array}$ \\
\hline Voluntariness & 0.375 & -0.1 & 0.157 & 0.157 \\
\hline Reducibility & 0.333 & $0.07 *$ & 0.111 & not considered \\
\hline Knowledge, experience & 0.875 & 0.08 & 0.13 & 0.13 \\
\hline Endangerment & 0.667 & 0.61 & 1.0 & 1.0 \\
\hline Subjective damage rating & 1.0 & not asked & 0 & not considered \\
\hline Subjective recurrence frequency & 0.875 & 0.2 & 0.319 & 0.319 \\
\hline Future increase $\left(p a f_{f i}\right)$ & not considered & 0.22 & not considered & 0.364 \\
\hline
\end{tabular}

*regression weight $\beta$ failed narrowly the sufficient level of statistical significance ( $p_{\beta}=0.089$ ), but the correlation coefficient $(r=0.07)$ was significant.

the workshop-PAF which had no corresponding survey variable, the PAF-value was set to a neutral PAF-value 1.

We obtained the following three equations, whereby in all runs, cases with at least one missing value due to nonresponse behavior of participants where excluded from the implementation.

- first implementation: workshop-PAF with $\mathrm{paf}_{i}$-values derived from survey (test sample) and experts-weights $a_{i, e x}$ as listed in Table 3 (column 2)

$r_{\text {perc }}=1 \cdot 1 \cdot \frac{p a f_{v} \cdot 0.375+p a f_{r} \cdot 0.333+p a f_{e x} \cdot 0.875+p a f_{d} \cdot 0.667+1 \cdot 1+p a f_{f} \cdot 0.875}{0.375+0.333+0.875+0.667+1+0.875}$

- second implementation: workshop-PAF with paf $_{i}$ values derived from survey (test sample) and laypersons_1-weights $a_{i, \text { lay_1 }}$ as listed in Table 3 (column 4)

$$
r_{\text {perc }}=1 \cdot 1 \cdot \frac{p a f_{v} \cdot 0.157+p a f_{r} \cdot 0.111+p a f_{e x} \cdot 0.13+p a f_{d} \cdot 1.0+1 \cdot 0+p a f_{f} \cdot 0.319}{0.157+0.111+0.13+1.0+0+0.319}
$$

- third implementation: questionnaire-PAF with $\mathrm{paf}_{i}$ values derived from survey (test sample) and laypersons_2-weights $a_{i}$,lay_2 as listed in Table 3 (last column)

$r_{\text {perc }}=1 \cdot 1 \cdot \frac{p a f_{v} \cdot 0.157+p a f_{e x} \cdot 0.13+p a f_{d} \cdot 1.0+p a f_{f} \cdot 0.319+p a f_{f i} \cdot 0.364}{0.157+0.13+1.0+0.319+0.364}$

The results of the first two runs are shown in Fig. 1. The calculated individual risks differ depending on the weights used. Thus, the model renders existing differences in risk perception of individuals and social groups.
Then the empirically generated questionnaire-PAF were implemented. The result of this third implementation run is represented in Fig. 2.

For a better comparison, the three model runs were plotted in a synoptic diagram shown in Fig. 3.

\section{Discussion}

\subsection{Model behaviour}

\subsubsection{Linear approach design}

The presented approach was designed following the method of heuristic model generation. A commonly used linear model was chosen as formal risk concept (cf. Eq. 1) to be expanded by an additional PAF term. These presumptions of linear model behaviour knowingly disregard findings of modern economic behaviour research (Kahneman and Tversky, 1979) describing a biased non-linear perception of risk in divergence from rational empirical effective risk. The linear model concept was nevertheless chosen in order to keep a first approach for individual risk perception as simple and easily implementable as possible. Following this objective, the parameters of the additional PAF-term expanding the principle risk equation were again defined to have linear and direct proportional impact.

\subsubsection{Flexible model applicability}

The presented formal model approach is designed to cope with deviating risk perceptions depending on different target groups (e.g. social groups such as experts, laypersons). Weights $a_{i}$ are used to render the varying effect of different 


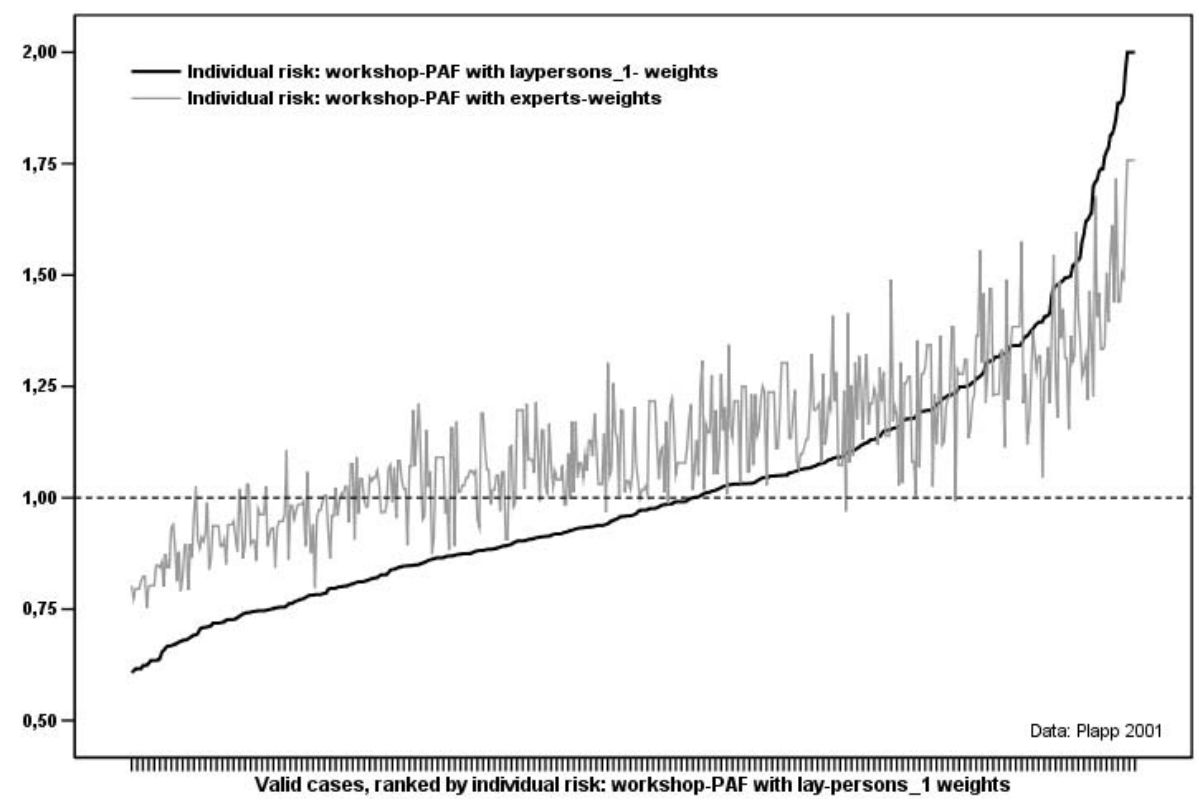

Fig. 1. Calculated individual perceived risk using laypersons_1-weights $a_{i, \text { lay_1 }}$ and experts-weights $a_{i, e x}$. The dotted horizontal line at 1.0 represents the effective individual risk $r_{\text {eff }}$ (on the $\mathrm{x}$-axis the persons (survey data sample) were plotted, on the y-axis the effective risk $r_{\text {eff }}$ ).

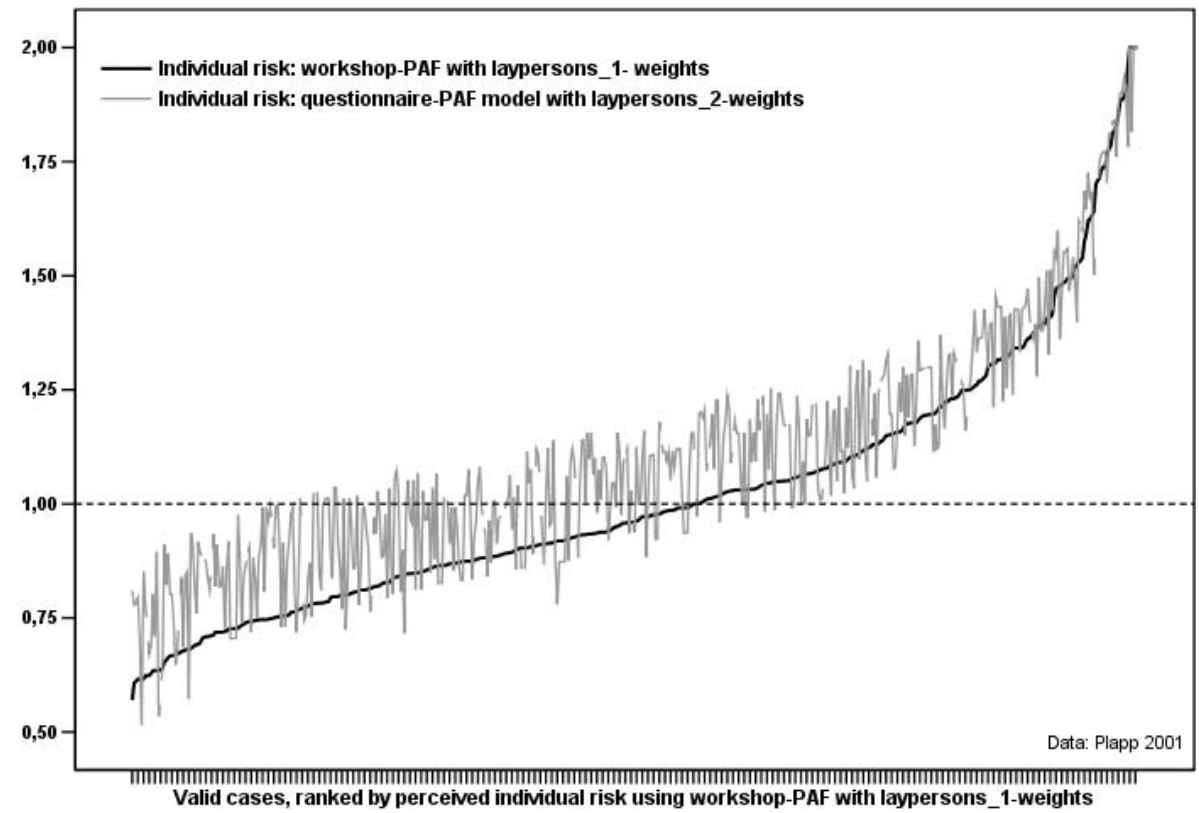

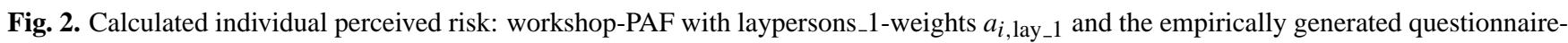
PAF with the respective laypersons_2-weights $a_{i, \text { lay_2}}$. The dotted horizontal line at 1.0 represents the effective individual risk $r_{\text {eff }}$ (on the $\mathrm{x}$-axis the persons (survey data sample) were plotted, on the $\mathrm{y}$-axis the effective risk $r_{\text {eff }}$ ).

PAF on the perception of individual risk, and hence to control their impact on the model result. Therefore, depending on weight parameterisation (laypersons' weights, experts' weights), identical PAF will evoke varying values for perceived individual risk as model result (cf. Fig. 3).
Due to its flexibility, the model approach is also able to cope with missing data for specific PAF in the empiric survey data. In the course of the presented implementation (cf. Sect. 4.3), the questionnaire design of the used real life survey data (Plapp, 2004) fitted the PAF definitions of the workshop-PAF quite well, a fact that facilitated the PAF 


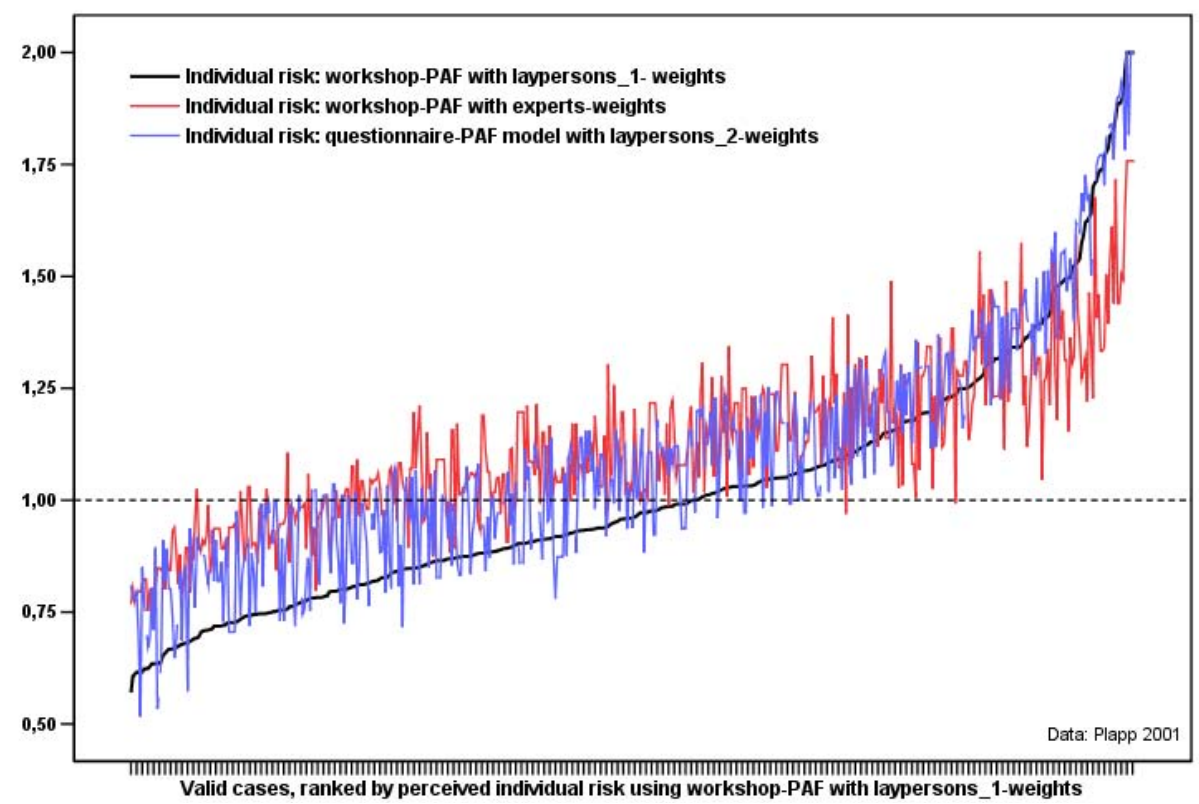

Fig. 3. Synoptic view of all three model implementations of calculated individual perceived risk: using the workshop-PAF with laypersons_1weights $a_{i, \text { lay_1 }}$ and experts-weights $a_{i, e x}$ (black, resp. red line) and the questionnaire-PAF model with the laypersons_2-weights $a_{i, \text { lay_2 }}$ (blue line). The dotted horizontal line at 1.0 represents the effective individual risk $r_{\text {eff }}$ (on the $\mathrm{x}$-axis the persons (survey data sample) were plotted, on the y-axis the effective risk $\left.r_{\mathrm{eff}}\right)$.

definition. However, one PAF was not measured in the survey according to the workshop-selection: 'subjective damage rating' $\mathrm{paf}_{e}$. The model approach is nevertheless well able to cope with such a vacancy. In such cases the impact of the specific PAF on the model result may be eliminated by using a neutral value of 1 .

\subsection{Model plausibility}

The model approach is explicitly designed to calculate plausible values for perceived individual risk, such as casualties or actual monetary values. The plausibility analysis illustrated in Sect. 4.1 .2 (case study) confirms a realistic model behaviour and plausible orders of magnitude for calculated perceived risk as model result.

Furthermore, the model equation concept is designed to keep over- as well as underestimation within a relatively narrow range when perceiving the effective individual risk. This is assured by an observance of PAF boundary conditions as defined in Sect. 3.2. However, PAF boundary conditions may well be defined individually in alternative ways in order to meet specific application needs, such as to narrow the underor the overestimation branch, or to increase the maximum possible under-/overestimation (e.g. $[0.1,1]$ or $[1,5])$.

\subsection{Model verification}

\subsection{1 "Real-life" implementation of the approach}

The presented implementation using actual empiric data (Sect. 4.3) asserts the applicability of the model approach. However, one cannot readily conclude from this attempt that experts and laypersons differ in their perception of individual risk. The three implementations may only display differences in PAF weights for the two groups, not in the magnitude of the respective PAF. Graph deviations shown in Figs. 1 and 2 are only caused by the use of different weights (experts vs. laypersons perspective) and - in Fig. 3 - by a slightly modified combination of PAF in the empirically deduced selection of PAF.

\subsubsection{Crucial peculiarities of the performed model applica- tion}

Derivations on risk acceptance itself may explicitly not be drawn from the presented model application. This is due to the fact that the model application merely aimed to investigate a method for PAF weight deduction and quantification. One and the same empiric dataset may however not be used for weight quantification as well as for PAF quantification (e.g. for the purpose of model verification), which would represent a short circuit. Therefore, an actual verification of the model itself could not yet be realised due to a lack of suitable and sufficiently comprehensive empiric data to quantify PAF. 
Hence, conclusions on effective risk acceptance with help of the presented model application using the available empiric data are not possible.

\section{Conclusions}

\subsection{Model achievements}

Proven applicability, flexibility, and plausibility affirm major benefits by the presented model approach.

The presented model concept brings significant improvements over present methods to assess risk aversion or acceptance. Known model approaches are based on the simplified assumption that perception and acceptance of a risk are merely a function of effective event consequences $e_{\text {eff }}$ (cf. Sect. 2.3). With rising magnitude damage is only accepted at low probabilities. However, perception and behaviour research (e.g. Kahneman and Tversky, 1979; Tversky and Kahneman, 1992) observed that besides the magnitude of an event consequences also its probability and some qualitative aspects of a risk are relevant for its perception and evaluation and are thus also relevant for its acceptance. The concept presented in this study provides a way to better integrate the relevant perception factors in the risk evaluation process.

\subsection{Fields of application and model limitations}

Risk perception is a complex issue, and so far no universal formal theories for risk perception, evaluation, or acceptance exist (cf. Sect. 1). The presented results hence represent a first attempt to quantify the factors driving the perception.

However, they also reflect those limitations of the psychometric paradigm which have been mentioned in the risk perception literature (e.g. Krimsky, 1992; Wilkinson, 2001): Both the empirically deduced selection of PAF and the workshop-PAF and their applications may only explain how risk perception differs, but not why it differs. In addition, the psychometric paradigm, and thus also the formal model proposed in this paper, generate only "snap shots" and consider neither the socio-cultural nor the historical context of risk perception, since they are highly individualistic and noncontextual approaches.

Taking into account these limitations, the presented approach may well be recommended to quantify risk perception by individual persons in a formal and technical way. Main fields of application may for instance be risk communication issues in illustrating differing perspectives of experts and non-experts. However, for decision making processes this model will have to be applied with caution, since it is by definition not designed to quantify risk acceptance or risk evaluation.

\subsection{Still to be done}

In accordance with Sect. 5.3.2, the quantitative accuracy of the model calculations in reference to observed individual risk perception are still to be tested extensively. Suitable and independent empiric data will be required for such a model verification. This will however require a major effort and considerable expenses for an inevitable quite comprehensive empiric survey.

Further challenges will be a comprehensive rating of the model validity concerning various conceivable application objectives, such as risk communications or educational purposes (model validation and evaluation).

\subsection{Future advancements}

Several known studies constate an overestimation of low occurrence probabilities and a underestimation of average or high occurrence probabilities of losses, known as the Prospect Theory (Kahneman and Tversky, 1979; Tversky and Kahneman, 1992; Eisenführ and Weber, 2003; Neumann and Morgenstern, 2004). Furthermore, with increasing extent of effective damage, the perceived damage rises to a lesser extent (declining graph gradient). Tversky and Kahneman (1992) define concave power functions for $e_{\text {eff,i }}$ (weighting function) and more complex s-shaped power function for $p_{\text {eff,i }}$ (value function). A future integration of Prospect Theory into the presented approach will take this biased nonlinear perception of risk into account. Then, the approach can be used to calculate the collectively perceived risk, too. The empirically deduced Prospect Theory functions may be comprehended as valid for an entire representative population due to the origin of their variables as median values. As a consequence, integration of Prospect Theory can turn the model more valid for normative processes as well (e.g. decision making in natural hazard mitigation).

Acknowledgements. This work was realised in the course of a project on behalf of and financed by the following agencies:

- Swiss National Platform for Natural Hazards (PLANAT)

- Swiss Federal Agency for Environment, Forest and Landscape (BUWAL)

- Swiss Federal Agency for Water and Geology (BWG)

- Swiss Federal Agency for Civil Defense (BABS)

The survey had been realised within the framework of the Postgraduate Programme "Natural Disasters" and carried out at the Institute for Insurance, Institute for Finance, Banking and Insurance, University of Karlsruhe (TH), Germany. It was financed by the German Research Foundation DFG, the Federal State of Baden-Wuerttemberg and in addition by the Stiftung Umwelt und Schadenvorsorge der SV-Versicherungen, Stuttgart, Germany.

Edited by: M.-C. Llasat

Reviewed by: L. Lopez and another referee 


\section{References}

Amman, W., Bischof, N., Bründl, M., Schneider, T., and Warner, K.: Teilprojekt B: Methoden-Evaluation. Schlussbericht, Tech. rep., PLANAT, 2004.

BABS: Katastrophen und Notlagen in der Schweiz (KATARISK). Eine Risikobeurteilung aus der Sicht des Bevölkerungsschutzes, Tech. rep., Bundesamt für Bevölkerungsschutz (BABS), http://www.bevoelkerungsschutz.admin.ch/internet/bs/de/home/ themen/Verbundsystem/gefaehrdungen/katarisk.html, access date: $25.1 .2005,2003$.

Belzer, R.: Getting beyond the grin and bear in the practice of risk management, Reliability Engineering and System Safety, 72, 137-148, 2001.

Bohnenblust, H.: Die Anwendung eines risikoorientierten Sicherheits-Modells zur Beurteilung der Neubaustreckentunnel der Deutschen Bundesbahn, in: Risikountersuchungen als Entscheidungsinstrument - Risk analysis as a decision tool, edited by: Yadigaroglu, Y. and Chakraborty, S., vol. 1, pp. 341361, Verlag TÜV Rheinland, Köln, 1985.

Bohnenblust, H. and Schneider, T.: Risk appraisal - can it be improved by formal decision models?, in: Uncertainty in risk assessment, risk management and decision making, edited by: Covello, V. T., Lave, L. B., Moghissi, A., and Uppuluri, V., vol. 4 of Advances in risk analysis, pp. 71-87, Plenum Press, New York/London, 1984.

Bohnenblust, H. and Slovic, P.: Integrating technical analysis and public values in risk-based decision making, Reliability Engineering and System Safety, 59, 151-159, 1998.

Brun, W.: Cognitive components in risk perception: natural vs. manmade risks, Journal of Behavioral Decision Making, 5, 117132, 1992.

BUWAL, ed.: Handbuch I zur Störfallverordnung StFV. Richtlinien für Betriebe mit Stoffen, Erzeugnissen und Sonderabfällen., Eidgenössische Drucksachen- und Materialzentrale (EDMZ), Bern, 1991.

DeChano, L. and Butler, D.: Analysis of public perception of debris flow hazard, Disaster Prevention and Management: An International Journal, 10, 261-269, 2001.

Eisenführ, F. and Weber, M.: Rationales Entscheiden, SpringerVerlag, Berlin, Heidelberg, New York, 3 edn., 2003.

Farmer, F.: Siting criteria - a new approach, in: Containment and siting of nuclear power plants, edited by: IAEA, vol. 1, pp. 303329, International atomic energy agency (IAEA), Wien, 1967.

Finlay, P. J. and Fell, R.: Landslides: risk perception and acceptance, Canadian Geotechnical Journal, 34, 169-188, 1997.

Fischhoff, B., Slovic, P., Lichtenstein, S., Read, S., and Combs, B.: How safe is safe enough? A psychometric study of attitudes towards technological risks and benefits, Policiy Sciences, 9, 127$152,1978$.

Fischhoff, B., Slovic, P., and Lichtenstein, S.: "The public" vs. "the experts": perceived vs. actual disagreements about risk of nuclear power, in: The analysis of actual versus perceived risks, edited by: Covello, V. T., Flamm, W. G., Rodricks, J. V., and Tardiff, R. G., vol. 1 of Advances in risk analysis, pp. 235-249, Plenum Press, 1981.

Geiger, G.: Risikobereitschaft und Risikoaversion in der Theorie rationaler ökonomischer und technischer Entscheidungen, in: Gesellschaft - Ethik - Risiko, Ergebnisse des PolyprojektWorkshop vom 23-25 November 1992, edited by: Ruh, H. and
Seiler, H., vol. 1, pp. 17-47, Birkhäuser, Basel, Boston, Berlin, 1993.

Griesmeyer, J. M.: Risk aversion of the public or risk proneness of experts?, Transactions of the american nuclear society, 41, 446447, 1982.

Heinimann, H. R.: Risk Management - a framework to improve effectiveness and efficiency of resource management decisions, in: 23rd session of the European Forestry Commission's working warty on the management of mountain watersheds, edited by: Greminger, P., vol. 1, pp. 16-19, Bundesamt für Wald, Umwelt und Landschaft (BUWAL), Davos, 2002.

Jasanoff, S.: The political science of risk perception, Reliability Engineering and System Safety, 59, 91-99, 1998.

Kahneman, D. and Tversky, A.: Prospect Theory: an analysis of decision under risk, Econometrica, 47, 263-291, 1979.

Karger, C. and Wiedemann, P.: Kognitive und affektive Komponenten der Bewertung von Umweltrisiken, Zeitschrift für experimentelle Psychologie, 45, 334-344, 1998.

Kasperson, R. E., Renn, O., Slovic, P., Brown, H. S., Emel, J., Goble, R., Kasperson, J. X., and Ratick, S.: The social amplification of risk: a conceptual framework, Risk Analysis, 8, 177-187, 1988.

Krimsky, S.: The role of theory in risk Studies, in: Social theories of risk, edited by Krimsky, S. and Golding, D., pp. 3-22, Praeger, Westport/London, 1992.

Lima, M.: Dam failure versus flood risk perception, in: Dams and safety management at downstream valleys, edited by: Betamio de Almeida, T. and Viseu, A., pp. 103-110, Balkema, Rotterdam, 1997.

Marris, C., Langford, I., Saunderson, T., and O'Riordan, T.: Exploring the "psychometric paradigm": comparisons between aggregate and individual analyses, Risk Analysis, 17, 303-312, 1997.

Merz, H. A., Schneider, T., and Bohnenblust, H.: Bewertung von technischen Risiken, Beiträge zur Strukturierung und zum Stand der Kenntnisse. Modelle zur Bewertung von Todesfallrisiken., vol. 1, vdf Verlag der Fachvereine, Zürich, 1995.

MünchenerRück: Naturkatastrophen in Deutschland. Schadenerfahrungen und Schadenpotentiale, Tech. rep., Munich Re, München, 1999.

NDK: Begriffe, NDK "Risiko und Sicherheit", 2001.

Neumann, J. and Morgenstern, O.: Theory of games and economic behavior, Princeton University Press, 2004.

Pidgeon, N.: Risk assessment, risk values and the social science programme: why we do need risk perception research, Reliability Engineering and System Safety, 59, 5-15, 1998.

Plapp, T.: Risk perception survey natural hazards summer 2001, unpublished data, Postgraduate Programme Natural Disasters and Insitute for Insurance, Universität Karlsruhe, Germany, 2001.

Plapp, T.: Wahrnehmung von Risiken aus Naturkatastrophen. Eine empirische Untersuchung in sechs gefährdeten Gebieten Süd- und Westdeutschlands, vol. 2 of Karlsruher Reihe II: Risikoforschung und Versicherungsmanagement, Verlag für Versicherungswirtschaft, 2004.

Plapp, T. and Werner, U.: Understanding risk perception from natural hazards: examples from Germany, in: CENAT-Workshop RISK 21, Coping with risks due to natural hazards in the $21 \mathrm{st}$ century, edited by: CENAT, Balkema, Rotterdam, in press, 2006.

Renn, O.: The role of risk perception for risk management, Engineering and System Safety, 59, 49-62, 1998. 
Rohrmann, B.: Risk perception research. Review and Documentation. Revised Edition, Research Center Juelich, Program group Man, Environment, Technology, Risk Communication Studies 69, Juelich, 1999.

Rowe, G. and Wright, G.: Differences in expert and lay judgements of risk: myth or reality?, Risk Analysis, 21, 341-356, 2001.

Saaty, T. L.: Decision making for leaders. The analytic hierarchy process for decisions in a complex world, RWS Publications, 3 edn., 2001.

Sandman, P. M.: Risk communication: facing public outrage, 1987.

Sandman, P. M.: Hazard versus Outrage in the public perception of risk, in: Effective risk communication: the role and responsibility of government and nongovernment organizations, edited by Covello, V. T., McCallum, D. B., and Pavlova, M. T., vol. 4 of Contemporary issuss in risk analysis, pp. 45-49, Plenum Press, New York, 1989.

Sandman, P. M.: Managing outrage: a primeur, Engineering News-Record, pp. A19-A23, http://www.psandman.com/ articles/amsaside.htm; access date: April 31, 2006, 1999a.

Sandman, P. M.: Risk = Hazard + Outrage. Coping with controversy about utility risks, Engineering News-Record, pp. A19A23, http://www.psandman.com/articles/amsa.htm; access date: April 31, 2006, 1999b.

Siegrist, M., Gutscher, H., Orlow, P., and Yoker, m.: Hochwassergefahren in der Schweiz: Risikobewusstsein in der Bevölkerung und die Implikationen für eine erfolgreiche Risikokommunikation, Schlussbericht, Tech. rep., Universität Zürich, Sozialforschungsstelle, 2004.

Simon, H. A.: A behavioral model of rational choice, Quarterly Journal of Economics, 111, 99-118, 1955.

Simon, H. A.: The science of the artificial, MIT Press, Cambridge (Mass.), 2 edn., 1966.

Sjöberg, L.: Factors in risk perception, Risk Analysis, 20, 1-11, 2000a.
Sjöberg, L.: The methodology of risk perception research, Quality and Quantity, 34, 407-418, $2000 \mathrm{~b}$.

Skjong, R. and Wentworth, B. H.: Expert judgement and risk perception, in: Offshore and polar engineering conference, ISOPE, vol. IV, pp. 537-544, Stavanger, 2001.

Slovic, P.: Perception of risk, Science, New series, 236, 280-285, 1987.

Slovic, P.: Perceptions of risk: reflections on the psychometric paradigm, in: Social theories of risk, edited by: Krimsky, S. and Golding, D., pp. 117-152, Praeger, Westport/ London, 1992.

Slovic, P.: The perception of risk, Bertram/Ingram, 2000.

Slovic, P., Fischhoff, B., and Lichtenstein, S.: Perceived risk: psychological factors and social implications, Proceedings of the Royal Society of London. Series A, Mathematical and Physical Sciences, 376, 17-34, 1981.

Slovic, P., Fischhoff, B., and Lichtenstein, S.: Risk Aversion, social values, and nuclear safety goals, Transactions of the american nuclear society, 41, 448-449, 1982.

Slovic, P., Fischhoff, B., and Lichtenstein, S.: The psychometric study of risk perception, in: Risk evaluation and management, edited by Covello, V. T., Menkes, J., and Mumpower, J., vol. 1 of Contemporary issues in risk analysis, pp. 3-24, Plenum Press, New York, 1986.

Troxler, C., Guenter, R., and Bohnenblust, H.: Schutz vor Naturgefahren, Schweizer Ingenieur und Architekt, 39, 1035-1040, 1989.

Tversky, A. and Kahneman, D.: Advances in Prospect Theory: cumulative representation of uncertainty, Journal of Risk and Uncertainty, pp. 297-323, 1992.

Wilkinson, I.: Social theories of risk perception: at once indispensable and insufficient, Current Sociology, 49, 1-22, 2001. 